\title{
Bernardo Soares: disolución del autor, autonomía de la obra, afirmación de los sueños
}

\section{Bernardo Soares: autos dissolution, work autonomy, affirmation of dreams}

\author{
Claudia Patricia Fonnegra Osorio* \\ Paola Andrea Fonnegra Osorio ${ }^{* *}$
}

"Sentí hoy, de repente, una sensación absurda y justa. Me di cuenta en un mínimo relámpago, de que no soy nadie. Nadie, absolutamente nadie”.

"todo es absurdo, y el sueño es todavía lo que menos lo es"

Bernardo Soares

\section{Resumen}

Desde una perspectiva hermenéutica, este texto busca analizar cómo en El libro del desasosiego de Bernardo Soares tiene lugar la presencia de fenómenos literarios catalogados por Blanchot y Foucault como desaparición del autor y afirmación de la autonomía de la obra, se trata de elementos que dan cuenta de crisis identitarias características del sujeto moderno, de las cuales el poeta portugués busca escapar a partir de la afirmación de los sueños.

Palabras clave: Autor, obra, literatura, modernidad, fragmentación, sueños.

\section{Abstract}

From a hermeneutical perspective, this paper analyzes how The book of Disquietude of Bernardo Soares has an influence of some literal phenomena catalogued by Blanchot and Foucault as author vanishing and the work autonomy affirmation. It is

\footnotetext{
* MSc en Estudios Humanísticos y Especialista en Hermenéutica Literaria de la Universidad EAFIT. Licenciada en Filosofía de la Universidad de Antioquia. Docente de cátedra de la Universidad de Antioquia. Integrante del grupo de Investigación en Filosofía Política del Instituto de Filosofía de la Universidad de Antioquia. Correo electrónico: claudiafonnegra@gmail.com

* $\quad$ Estudiante de Maestría en Literatura Colombiana. Universidad de Antioquia. Docente de cátedra de la Universidad de Antioquia y del Tecnológico de Antioquia. Correo electrónico: panafonos@gmail.com
} 
about some elements that deal with the identity crisis characterized by the modern subject, from this Portuguese poet tries to escape by means of the affirmation of dreams.

Key words: Author, work, literature, modernity, fragmentation, dreams.

\section{Introducción}

La figura de Fernando Pessoa, el poeta de los heterónimos, da cuenta de lo que Blanchot y Foucault llamaron disolución u olvido del autor. Testigo escéptico de las promesas de progreso ilustradas, Pessoa experimenta la disolución de sí mismo dando lugar a la configuración de seres plurales. Pero a diferencia del hombre que escribe bajo el velo de un seudónimo para ocultar su verdadero rostro, el escritor portugués encarna la imagen de un ser fragmentado y escindido, carente, inacabadado, irreducible a una categoría fija del pensamiento plenamente consciente de sí misma.

Pessoa vive y se abandona en la escritura, en ella se disuelven su biografía y condiciones existenciales particulares, dando lugar a voces disímiles, con cadencias y estilos diversos. Esto se deja ver explícitamente en la carta que escribe a Adolfo Casais Monterio, en la que intenta dar cuenta del origen de su creación múltiple "Gradué las influencias, conocí amistades, oí dentro de mí, las discusiones y la divergencia de criterios, y en todo ello me parece que fui yo, creador de todo, lo menos que allí hubo, parece que todo ocurrió independiente de mí” (Pessoa, 1990, p. 325).

En la literatura de Fernando Pessoa, la imagen clara y soberbia del sujeto moderno no es soberana, el pensamiento no puede concebirse como la condición que da lugar a la certeza de la existencia, la confianza en la razón se esfuma y, con ella, la creencia en la autonomía de la voluntad. Al aproximarnos a su escritura, se debe dejar a un lado la solidez propia del razonamiento discursivo para dar lugar a la perplejidad, al asombro, a las incertidumbres, a las preguntas, a las negaciones e indiferencias de un hombre que no es uno sino muchos, que no descubre la realidad sino que la inventa. 
Desde niño tuve la tendencia de crear en torno a mí un mundo ficticio, de rodearme de amigos y conocidos que nunca existieron. (No sé, bien entendido, si realmente no existieron, o si soy yo quien no existe. En estas cosas, como en todas, no debemos ser dogmáticos). Desde que me conozco como siendo aquello a que llamo yo, me acuerdo de precisar mentalmente, en figura, movimientos, carácter e historia, varias figuras irreales que eran para mí tan visibles y mías como las cosas de aquello a lo que llamamos, acaso abusivamente la vida real (p. 322-323).

Poco a poco, o en ocasiones de un tirón, los personajes ficticios que acompañaron a Pessoa desde su niñez cobraron realidad en su escritura, tuvieron un nombre, una historia, una concepción del sentido de la existencia, una determinación mística, un oficio; además de penas, sensaciones y sueños.

Moldeados por manos atadas a una vieja máquina de escribir, llegaron con fuerza a nuestro universo literario Ricardo Reis, Álvaro de Campos, Alberto Caerio, Antonio Mora, Bernardo Soares (entre otros), quienes sostuvieron entre sí álgidas discusiones y, a su vez, encontraron afinidades profundas. Bernando Soares, sin embargo, ocupa una posición singular, ya que como el mismo Pessoa lo reseña "Es un semiheterónimo porque, no siendo la personalidad la mía, es, no diferente de la mía, sino una simple mutación de ella. Soy yo menos el raciocinio y la afectividad" (p. 327).

En El libro del desasosiego de Bernando Soares se encuentra una serie de fragmentos en los que es posible rastrear múltiples reflexiones en torno a la vida y su carácter enigmático, hay en este texto bellísimos apuntes dedicados a la cotidianidad, a la pesadez de la rutina, de la vida urbana y de sus transeúntes; allí Bernardo Soares presenta una visión escindida de sí mismo, pero también de su obra y, en general, de la literatura; se trata de tópicos literarios que coinciden con aquello que Blanchot y Foucault denominaron disolución del autor y autonomía de la obra, veamos por qué: 


\section{Disolución del autor:}

Blanchot en reiteradas ocasiones se refiere a la escritura como ejercicio constante, pero a diferencia de los autores románticos que exaltaron la producción literaria y al genio que le dio lugar, Blanchot alude a una experiencia desgarradora, la cual, en lugar de hablar en nombre de un contacto suprasensible o desde una inspiración excepcional, habla desde la soledad de quien escribe, que no puede confundirse ni con el aislamiento, ni con el regocijo de quien necesita de la ausencia de ruido, de la huída de la multitud para potencializar su trabajo. Este tipo de escritor no revela verdades, no reivindica su oficio, su ocio, su labor; tampoco quiere ser alabado como artista, como personaje único, no pretende crear escuelas, movimientos, géneros o doctrinas con finalidades universales y absolutas.

La soledad del hombre descrito por Blanchot está arraigada en la ausencia misma de quien escribe, en la pérdida de su individualidad, en suma, en su silencio. "Este silencio tiene su fuente en la desaparición a la que está invitado aquel que escribe” (Blanchot, 1992, p. 21). Desconfigurarse, perderse, percibir la sensación de no ser, son los principios de la actividad creadora. "Lo que en él habla, es que de una u otra manera ya no es él mismo, ya no es nadie" (p. 22).

En la misma línea de sentido, Foucault señala que ante el surgimiento de la literatura ${ }^{1}$, la figura de autor, en tanto propietario

Foucault señala que la literatura surge en la modernidad. No obstante, a las narraciones del siglo XVII y a las de los siglos que las precedieron las denomina "literatura clásica". Refiriéndose concretamente al siglo XVII Foucault, plantea que la literatura tiene que ver con la recepción de un lenguaje cercano, familiar, el cual da cuenta de un saber que se perpetúa bajo la forma del recuerdo. "En esta época la relación que constituía la literatura en la época clásica sólo era un asunto de memoria, de familiaridad, de saber: era un asunto de recepción" (Foucault, 1996, p. 62). A partir del siglo XIX, concretamente de la escritura de Mallarmé, Foucault realiza una serie de reflexiones en torno a la pregunta ¿̇qué es literatura? Esta es presentada en la modernidad como un espacio vacío en el que se abre la indagación por la razón de ser de su existencia. Esta pregunta, sin embargo, no es exterior a la literatura, es decir, no se plantea desde la perspectiva del analista que, al tomar distancia sobre el objeto de su estudio, permite examinarlo de forma imparcial y objetiva, no es a la positividad del lenguaje a la que Foucault se dirige. En esta nueva aproximación a lo que sería el nacimiento de la literatura, conceptos como memoria, apropiación, identidad perderían su lugar privilegiado. Así que, Foucault alude a conceptos tales como trasgresión, 
de un discurso que dirige y controla, se disuelve, ya que no se trata de un individuo con un pasado, con proyectos futuros, con características particulares que den cuenta de su personalidad. No hay entonces un ser con una identidad fija que protagonice el acto de escribir. Es posible comprender esta difícil tesis en tanto que el escritor del que habla Foucault se presenta como hijo de una época de crisis, donde las relaciones intersubjetivas son socavadas por diversos dispositivos de poder que lo dejan en una suerte de orfandad, en donde la certeza de una identidad unívoca desaparece.

Este abandono del autor en la escritura es padecido por Bernardo Soares, semiheterónomo de Pessoa. Observemos algunos de sus apuntes:

Envidio - pero no sé si envidio- a aquellos de quienes puede escribirse una biografía, o que pueden escribir la suya propia. En estas impresiones sin nexo, ni deseo de nexo, narro indiferentemente mi autobiografía sin acontecimientos, mi historia sin vida. Son mis confesiones, y, si en ellas nada digo, es porque nada tengo que decir... (Pessoa, 1984, p. 27).

Se ve pues que al negar o poner en tela de juicio la existencia del "yo", hay una especial afinidad entre Bernardo Soares y la postura de los pensadores franceses arriba citados. Como señala María Cecilia Salas Guerra:

Pessoa existe como una fuente abierta de escritura, no sólo la del Libro, también la del drama em gente; la del poema dramático, imposible que constituye el Fausto, la de Antinoo -con su terrible fuerza contenida- y Oh Marinheiro -ese extraño drama estático. Escritura que viene a materializar o a poner en acto lo que más adelante Michel Foucault, en Las palabras y las cosas, y en El pensamiento del afuera, designará como desaparición, el dejar de aparecer, la esfumación, desvanecimiento o disolución (éffacement) del Hombre-sujeto. De igual modo, y como consecuencia de esa disolución, la escritura que es Pessoa anticipa también la apuesta en cuestión de la figura del autor -y en ello Pessoa es del todo próxima a Musil, Kafka, Beckett, Joyce- que desaparece

lenguaje de lo neutro, fin de la subjetividad, los cuales le permitirían aproximarse a lo que denomina la esencia del ser del lenguaje. 
en beneficio de la obra o que es despedido por la obra misma. De esta desaparición/despedida del autor hablarán más tarde -aunque sin mencionar explícitamente la obra de Pessoa, y ello quizá por desconocimiento o por desestimación - tanto Michel Foucault en "¿qué es un autor?” y De lenguaje y literatura, como Blanchot en El espacio literario, El libro por venir y El diálogo inconcluso (Salas, 2006, p. 108).

Bernardo Soares escribe desde su silencio, desde la indeterminación. Podríamos afirmar, siguiendo a Blanchot y Foucault, que ese ser que escribe no es un representante del pensamiento cartesiano o kantiano, es un "él", un "alguien" carente de historia, de luminosidad, de éxito, de popularidad o de júbilo. Aquí se pronuncia un ser sin biografía unitaria, sin acciones grandiosas o banales que lo identifiquen en su singularidad. Lo que habla es contingencia pura; no hay la consciencia de un yo que unifique representaciones, no hay el reconocimiento de una voluntad que autodetermine una cadena de acciones espontáneas y libres. En su lugar tenemos "Una voluntad muerta y una reflexión que la arrulla, como a un hijo vivo...” (Pessoa, 1984, p. 28).

Veamos a continuación otro fragmento en el que se revela la desaparición de la certeza de la figura del yo.

Ni yo mismo sé si este yo, que os vengo exponiendo a lo largo de estas páginas, existe realmente o no es más que un concepto estético y falso que yo hice de mí mismo. Sí, sí, así es. Me vivo estéticamente en otro. Esculpí mi vida como una estatua de materia ajena a mi propio ser. A veces no me reconozco, tan exterior me hice a mí mismo, y tan de modo puramente artístico empleé mi conciencia de mí mismo. ¿̇uién soy yo por detrás de esta realidad? No lo sé. Debo ser alguien. Y si no procuro vivir, actuar, sentir, es - podéis creerlo- para no perturbar las líneas dibujadas de mi personalidad supuesta. Quiero ser tal como quise ser y no soy. Si cediera, me destruiría. Quiero ser una obra de arte, del alma por lo menos, ya que del cuerpo no puedo serlo. Por eso me esculpí en calma y en extrañamiento y me coloqué en invernadero, lejos de los aires frescos y de las luces claras- donde mi artificiosidad, flor absurda, pueda florecer en lejana belleza (p. 132).

Que el autor desaparezca significa que no existe un sujeto creador que pueda dar cuenta del origen de su obra. Quien escribe no sigue un 
principio trascendente, no atiente al llamado de la musa, no comunica un mensaje secreto, no defiende una visión del mundo; paradójicamente no cuenta una historia, no emite un mensaje. Pero a su vez, no puede dejar de escribir:

Para mí, escribir equivale a despreciarme; pero no puedo dejar de escribir. Escribir es como una droga que me repugna y tomo, el vicio que desprecio y en el que vivo. Hay venenos necesarios, y los hay sutilísimos, compuestos por ingredientes del alma, hierbas recogidas en los rincones de las ruinas de los sueños, amapolas negras encontradas junto a las sepulturas de los propósitos, hojas largas de árboles obscenos que agitan sus ramas en las orillas oídas de los ríos infernales del alma (p. 170).

Ser del afuera, del extrañamiento, de la negatividad. Fuga de sí mismo, conciencia que no deviene autoconsciente, negación de la dialéctica hegeliana, es lo que encontramos en la estética contenida en el Libro del desasosiego. Sin embargo, no hay en ella una renuncia deliberada a la unidad, tampoco una crítica explícita a los pilares del pensamiento moderno, mucho menos un propósito, al modo nihilista, de negarlo todo, de destruirlo todo, de no dejar verdad en pie. Por ello, Bernardo Soares asegura: "Yo no soy pesimista, soy triste" (p. 145). Desterrado del mundo y forastero de sí mismo ve en la facultad de soñar, en el arte, en la escritura, el único modo de llevar a cabo la vida y su pesadez. De este modo vive aquel que se percibe a sí mismo como parte de aquellos "Nietos del destino e hijastros del Dios, que se casó con la Noche Eterna cuando esta enviudó del caos que nos procreó” (p. 55).

\section{Autonomía de la obra}

Para Blanchot, "La palabra obray la unidad que designa probablemente son tan complejas como la individualidad del autor” (1992, p. 335). Esto es así porque la obra se presenta como intransitiva, espacio cerrado que no remite a una exterioridad. Ahora, esto no significa, como lo propone el estructuralismo, que una obra deba leerse independiente de su contexto cultural y que, por lo tanto, deba ser analizada a partir de sus indicios, informantes, secuencias, esquemas actanciales, en fin, de toda una 
serie de estructuras internas que permitan desentrañar la forma de un texto ${ }^{2}$. No se trata de eso; si el autor desaparece, la noción clásica de obra también lo hace, queda en su lugar un espacio imposible de aprehender.

Sólo importa la obra, la afirmación que hay en la obra, el poema en su singularidad estricta, el cuadro en su espacio propio. Sólo importa la obra, pero finalmente la obra no está ahí más que para conducir a la búsqueda de la obra; la obra es el movimiento, que nos conduce hacia el punto puro de la inspiración de la que proviene y que parece que no puede alcanzar más que desapareciendo (p. 236-237).

La obra es lugar del equívoco, de la pérdida, del error. Lo anterior tiene su razón de ser en el abismo existente entre la literatura y la obra: la obra busca la literatura pero no la encuentra, dejando sólo tras de sí el intento de aprisionar su esencia.

\begin{abstract}
Pero, precisamente, la esencia de la literatura es sustraerse a toda determinación esencial, a toda afirmación que la estabilice o que incluso la realice: la literatura nunca está ahí ya, siempre está por encontrar o por reinventar (...). Quien afirma la literatura en sí misma no afirma nada. Quien la busca, no busca sino aquello que se oculta, quien la encuentra no encuentra más que lo que está más acá o, aún peor, más allá de la literatura. Por eso, finalmente, lo que cada libro persigue como la esencia de lo que ama y querría apasionadamente descubrir es la no literatura (Blanchot, 2005, p. 237).
\end{abstract}

En la misma línea de sentido, Foucault asegura que el escritor a través de su obra intenta aprisionar la esencia de la literatura sin lograrlo. De ahí que su búsqueda sólo se realice en el ritual previo a la literatura, en el momento en que la página permanece en blanco.

Por consiguiente, desde que la página en blanco comienza a rellenarse, desde que las palabras comienzan a trascribirse en esta superficie que es todavía virgen, en ese momento cada palabra es en cierto modo absolutamente decepcionante en relación con la literatura, porque no hay ninguna palabra que pertenezca por esencia, por derecho de naturaleza a la literatura (Foucault, 1996, p. 67).

2 Para ampliar la propuesta de análisis del estructuralismo véase el texto Análisis estructural del relato. 
Este tipo de escritura obedece a una actividad inaprensible incluso por quien escribe. Podemos ver entonces como "la soledad que alcanza el escritor mediante la obra se revela en que ahora escribir es lo interminable, lo incesante" (Blanchot, 1992, 20).

Observemos ahora la percepción que de su obra presenta Bernardo Soares:

Releo con lucidez, demoradamente, fragmento a fragmento, todo lo que he escrito. Y creo que todo es nulo y que más hubiera valido no haberlo hecho. Las cosas logradas, sean frases o imperios, tienen, por haberse logrado, aquella peor parte de las cosas reales que es el saber que son perecederas. No es esto, sin embargo, lo que siento y me duele de todo lo que hice, en estos momentos prologados en que releo. Lo que me duele es que no valió la pena hacerlo, y que el tiempo que perdí haciéndolo no lo gané sino en la ilusión, ahora desecha, de que valía la pena haberlo hecho (...) todo lo que hacemos, en el arte o en la vida, es copia imperfecta de aquello que pensábamos hacer (Pessoa, 2002, p. 186).

Pero esta escritura, pese a lo anotado, y aunque parezca contradictorio, también posibilita la existencia, cobra la libertad que el escritor ha perdido

Hay metáforas más reales que las personas que pasan por la calle. Hay imágenes en los rincones de los libros que viven más nítidamente que muchos hombres y mujeres. Hay frases literarias que tienen una personalidad absolutamente humana. Hay fragmentos de párrafos míos que me hielan de pavor, de tal modo los siento claramente como seres humanos, tan bien perfilados contra las paredes de mi cuarto, por la noche, en la sombra. He escrito frases cuyo sonido, leídas en voz baja o en alta voz -es imposible ocultar su sonido-, es absolutamente el de una cosa que ganó exterioridad absoluta y alma por completo (p.174).

Así que, la muerte del autor es el triunfo de la obra, pero no nos referimos a ella en su sentido clásico, sino como apertura, potencialidad, espacio literario por descubrir. 


\section{Conclusión}

Para Bernardo Soares, la escritura permite la existencia y, sin embargo, anula la individualidad, la obra cobra fuerza, pero el lenguaje adquiere un nuevo sentido, por lo tanto sus funciones y nociones clásicas resultan insuficientes para pensar este tipo de producciones: al desaparecer el destinador, desaparece el destinatario y, con ello, la definición de mensaje; en suma, todas aquellas categorías que Jakobson (1981) calificó como indispensables para descifrar el sentido de un acto comunicativo. Tenemos pues que "el escritor pertenece a un lenguaje el cual nadie habla, que no se dirige a nadie, que no tiene centro, que no revela nada. Puede creer que se afirma en el lenguaje, pero lo que afirma está completamente privado de sí” (Blanchot, 1992, p. 20).

Esta es una escritura sin reposo, sin sosiego, indescifrable, carente de forma, inacabada, es la que vuelve sobre sí misma siempre renovada, la que busca y se busca sin hallarse, la que intenta pronunciar lo indecible, la que perturba, la que aniquila, con la que nunca se está plenamente conforme. Escritura que realiza el ideal del arte mientras se produce, pero que desdice de sí misma cuando pretende estar acabada; escritura que no ve en sus resultados más que banalidad, muñecos de paja inconclusos vaciados de contenido, nunca realizados ${ }^{3}$.

Olvidarse de sí, labrar caminos y no volver a recorrerlos, indicar señales, luego perderlas. Bernardo Soares experimenta sin gloria los acontecimientos de un mundo masificado, inauténtico, el cual hubo que inventar de nuevo para poder continuar sobreviviendo, sin declinar, soñando...

En medio de mi trabajo de cada día, trabajo sin color, igual e inútil, tengo visiones de fuga, vestigios soñados de islas lejanas, fiestas en avenidas de parques de otras eras, otros paisajes, otros sentimientos, otros yo. Pero reconozco, entre dos asientos, que si tuviera todo eso, nada de eso sería mío (...). Puedo imaginarlo todo porque no soy nada.

3 Así lo expresa el autor: "Y al final, hoy, releyendo, veo como revientan mis muñecos, como se les sale la paja por entre las costuras, vaciándose sin haber sido ...” (Pessoa, 2002, 187) 


\section{Referencias bibliográficas}

Blanchot, M. (1992). El espacio literario. Barcelona: Paidós.

----- (2005). El libro por venir. Madrid: Trotta.

Foucault, M. (1996). Lenguaje y literatura. Barcelona: Paidós,

Jakobson, R. (1981). Lingüística y poética. Madrid: Ediciones Cátedra.

Pessoa, F. (2002). Libro del desasosiego. Barcelona: El Acantilado.

----. Obra poética. (1990). Tomo I. Barcelona: Ediciones 29.

Salas, M. “Trastornos de la escritura, imposibilidad de la obra”. En: Co-herencia, Vol. $3 . \mathrm{N}^{\circ} 5$ (Julio-Diciembre), Medellín, Universidad EAFIT, pp. 105-119, 2006.

Tanagra, Pedro, ed. (1998). Análisis estructural del relato. México: Premiá Editora de Libros. 